\title{
EFFECTS OF THE LOCKDOWN ON PERCEIVED STRESS AND WELL-BEING: A STUDY ON ITALIAN UNIVERSITY IN THE FIRST PERIOD OF ISOLATION DUE TO COVID-19
}

\author{
Oronzo Parlangeli, Paola Palmitesta, Stefano Guidi, Ileana Di Pomponio, Margherita Bracci \\ and Enrica Marchigiani \\ Department of Social, Political and Cognitive Sciences \\ University of Siena, Italy
}

\begin{abstract}
This study investigated the effect of the isolation during the lockdown period on psychological distress and well-being in a sample of professors $(\mathrm{N}=150)$, students $(\mathrm{N}=150)$ and technical administrative staff $(\mathrm{N}=150)$ from 3 Italian Universities, in the region of Tuscany. We administered a self-reported online questionnaire to collect socio-demographic information, investigate issues in work and study life, and assess the level of perceived stress and psychological well-being. The results of this study indicate that under conditions of isolation perceived stress levels are increased, and this is related to the experience of an unpleasant house environment. This is also significantly predicted by the occurrence of issues with online lectures and administrative activities for university professors or by having issues with managerial support for technical administrative staff. On the other hand, for university students, a good relationship with other students is of great importance to maintain a high level of mental well-being and being male is a protective factor. Evidently, aspects related to the deprivation of opportunities for peer relationships are experienced as particularly problematic.
\end{abstract}

\section{KEYWORDS}

Perceived Stress and Well-Being, Quarantine due to COVID-19, Studying and Working at Distance

\section{INTRODUCTION}

The pandemic due to coronavirus disease (Covid-19) has forced countries all over the world to take severe social isolation measures to respond to the virus and control its spread. Several countries have been forced to impose many restrictions, social distancing and social isolation measures.

Starting from spring 2020, all Italian Schools and Universities had to transform face-to-face lessons in distance learning. The impact of these measures on behavior and psychological health is not yet clear, though, some researchers have begun to explore the psychological pressure that the pandemic and social isolation have had on general population (Wang et al., 2020), elderly (Mukhtar, 2020) children and adolescents (Shah et al., 2020; Wagner, 2020), university students (Cao et al., 2020; Duan and Zhu, 2020; Odriozola-González et al., 2020; Xiao, 2020).

Past studies have shown the negative impact of social isolation on various individual and organizational outcomes and on emotional and mental health (Courtin and Knapp, 2017; Hossain et al., 2020). All these studies underline that the conditions shared by the different populations under observation, that is isolation, worry for the own health and of their families as well as the concern for the economic impact, can increase the risk of anxiety and mental distress in different groups of people, from children to adults to elderly (Mukhtar, 2020; Rogowska et al., 2020; Shah et al., 2020; Al Issa and Jaleel, 2021).

With regard to university, in addition to the constraints and concerns just mentioned, very recent research highlights the worry for the difficulties that may be encountered in the learning process, teaching and working at a distance (Elmer et al., 2020; Sahu, 2020). On the one hand professors can find it difficult to support motivation and engagement in the learning process, to monitor how students learn or if they encounter difficulties (King et al., 2009; Watson and Sottile, 2010; Parlangeli et al., 2011; Timmis et al., 2016), and the distance teaching strategy exhibited unexpected challenges and concerns among university professors 
(Parlangeli et al., 2017; Akour et al., 2020; Sahu, 2020). Moreover, several studies highlighted the need for additional skills for online teaching (Angeli and Valanides, 2005; Kali et al., 2011; Baldwin et al., 2018), including technical and administrative aspects (e.g. using platforms/tools and organizing workflows).

On the other hand, it becomes more challenging for the students to maintain motivation and engagement, to keep up with the pace of study, and to keep in touch and benefit from face-to-face interaction with professors and colleagues (Parlangeli et al., 2018; Elmer et al., 2020; Shah et al., 2020).

Besides all this, technical administrative staff working at university usually have the challenge of attaining high levels of performance and face issues related to limited resources, poor communication and bureaucratic procedures (Kiplangat et al., 2016).

The aim of this study was to investigate the effect of the isolation during the lockdown period on psychological stress and well-being in a sample of university professors, students and technical administrative staff. To this aim several aspects of studying, teaching and working at a distance have been analyzed in order to understand how to implement effective strategies to prevent stress and negative consequences: the environment in which the lockdown period was lived, the adequacy of technological equipment and the distance learning activities.

\section{THE STUDY}

\subsection{Participants and Procedure}

The study involved 450 subjects from 3 Italian Universities, in the region of Tuscany, belonging to three groups: professors $(\mathrm{N}=150)$, students $(\mathrm{N}=150)$ and technical administrative staff $(\mathrm{N}=150)$. Participants took part in the study on a voluntary basis. They were invited via their university e-mail address to fill in an anonymous, self-reported online questionnaire that took about 15-20 minutes to be completed. Three versions of the questionnaire have been prepared for the study, dedicated respectively to university students, professors, and technical administrative staff. The delivery of the questionnaire began online in October 2020. The protocol of the study was approved by the Ethics Committee of Human and Social Sciences of the University of Siena.

\subsection{Measures}

The questionnaire included 55 questions, and it was structured in three sections. The first section was aimed at collecting socio-demographic information about participants. The second section (6 questions) was aimed at gathering information on aspects that were perceived as most problematic such as: attending or holding the lessons at a distance, online exams, the relations with other colleagues, keeping in touch with professors/students/technical administrative staff and obtaining or giving adequate information support from online institutional channels. Problems were rated on a 5-point Likert scale (from $0=$ 'not a problem at all' to $4=$ 'very much of a problem').

The third section had two scales (18 questions) related to the psychological impact of confinement due to COVID-19 pandemic. The level of perceived stress was measured with the four-item version of the Perceived Stress Scale (Cohen et al., 1983; Warttig et al., 2013), aiming at rating the frequency of perceived stressful situations during lockdown. The answers were collected on a frequency scale from $0=$ "Never" to $4=$ "Very often". The degree of psychological well-being was measured through the Italian version of the Warwick-Edinburgh Mental Well-Being Scale (WEMWBS) (Tennant et al., 2007; Gremigni and Stewart-Brown, 2011), a 12-item scale, which contains all positively worded items on different aspects of positive mental health, that estimate the individual's ability to manage and get through problematic or difficult situations in life. Answers were collected on a frequency Likert scale, from 1 ("Never") to 5 ("Always"). All the items in the second and third section of the questionnaire were referred to the first lockdown in Italy, March-May 2020. 


\subsection{Statistical Analyses}

Descriptive statistics were computed (mean and standard deviations for numeric variables, frequencies tables for nominal variables) for all the measures of interest. Univariate and Multivariate Analyses of Variance were conducted on quantitative variables while Chi Square Analyses were performed to explore the relation between categorical variables. Correlations were also computed among the different measures of stress, well-being and other issues related to living, studying and working during lockdown. Finally, two multiple regression models were used to assess predictors of stress and well-being.

\subsection{Results and Discussion}

\subsubsection{General Features of the Sample}

In the student and T.A. groups, participants were mostly females ( $76 \%$ and $65 \%$ respectively), while in the professors' group gender there is no significant difference in gender representativeness. The age range of the total sample was between 18 and 69 years, with different distribution among the three groups. Professors age range was between 27 to 69 years (Mean: 49.92, SD: 10.63), students age range was between 18 and 63 years (Mean: 23.85, SD: 7.5) and technical administrative staff age was between 28 to 66 years (Mean: 51.13, SD: 8.66).

Professors were mostly associate professors (36.7\%), researchers $(25.3 \%)$ and full professors $(22 \%)$, with a quite homogeneous distribution about seniority and had a full-time commitment $(96.6 \%)$.

Most of the students $(79 \%)$ were enrolled in a Bachelor's Degree program, as confirmed also by the fact that most of them were attending in the one of the first 3 years $(85.6 \%)$.

The distribution of technical administrative staff seniority was very homogeneous.

\subsubsection{Information about the Lockdown Period}

Table 1 presents distributions of perceptions about problematic conditions concerning the March-May 2020 lockdown period.

Table 1. Variables about quarantine/Isolation

\begin{tabular}{|c|c|c|c|c|c|c|c|c|}
\hline \multirow[b]{2}{*}{ Variable } & \multicolumn{2}{|c|}{ Professors } & \multicolumn{2}{|c|}{ Students } & \multicolumn{2}{|c|}{ T.A Staff } & \multirow[b]{2}{*}{$\mathbf{C h i}^{2}$} & \multirow[b]{2}{*}{$\mathbf{p}$} \\
\hline & $\mathbf{N}$ & $\%$ & $\mathbf{N}$ & $\%$ & $\mathbf{N}$ & $\%$ & & \\
\hline \multicolumn{9}{|l|}{ Risk of infection } \\
\hline Low risk & 10 & $6.7 \%$ & 14 & $9.4 \%$ & 6 & $4.1 \%$ & \multirow{4}{*}{46,112} & \multirow{4}{*}{0.000} \\
\hline Intermediate low risk & 36 & $24.2 \%$ & $75^{\dagger}$ & $50.3 \%$ & $36^{\dagger}$ & $24.5 \%$ & & \\
\hline Intermediate high risk & 69 & $46.3 \%$ & 51 & $34.2 \%$ & 69 & $46.9 \%$ & & \\
\hline High risk & 34 & $22.8 \%$ & $9^{\dagger}$ & $6.0 \%$ & $36^{\dagger}$ & $24.5 \%$ & & \\
\hline \multicolumn{9}{|l|}{ Restrictions } \\
\hline No restrictions & 56 & $37.3 \%$ & 46 & $30.9 \%$ & $77^{\dagger}$ & $52.0 \%$ & \multirow{4}{*}{23,517} & \multirow{4}{*}{0.003} \\
\hline No restrictions. DPI & 46 & $30.7 \%$ & 48 & $32.2 \%$ & 47 & $31.8 \%$ & & \\
\hline Partial isolation & 40 & $26.7 \%$ & 44 & $29.5 \%$ & $21^{\dagger}$ & $14.2 \%$ & & \\
\hline Total isolation & 8 & $5.3 \%$ & 11 & $7.4 \%$ & 3 & $2.0 \%$ & & \\
\hline
\end{tabular}


Quarantine at University

\begin{tabular}{|c|c|c|c|c|c|c|c|c|}
\hline No & 44 & $29.3 \%$ & $67^{\dagger}$ & $44.7 \%$ & $\mathbf{2 8}^{\dagger}$ & $19.2 \%$ & \multirow{2}{*}{23,069} & \multirow[b]{2}{*}{0.000} \\
\hline Yes & 106 & $70.7 \%$ & $\mathbf{8 3}^{\dagger}$ & $55.3 \%$ & 119 & $81.5 \%$ & & \\
\hline \multicolumn{9}{|l|}{ Who did you quarantine with } \\
\hline Family & 130 & $86.7 \%$ & 132 & $88.0 \%$ & 132 & $88.0 \%$ & & \\
\hline Roommates & 2 & $1.3 \%$ & 3 & $2.0 \%$ & 3 & $2.0 \%$ & 15,986 & 0.003 \\
\hline Alone & 17 & $11.3 \%$ & 15 & $10.0 \%$ & 15 & $10.0 \%$ & & \\
\hline \multirow[t]{2}{*}{$\begin{array}{l}\text { How many people did you quarantine } \\
\text { with }\end{array}$} & Mean & $S D$ & Mean & $S D$ & Mean & $S D$ & \multicolumn{2}{|l|}{$F_{(2,440)}$} \\
\hline & 2.84 & 1.552 & $3.46^{*}$ & 1.349 & 2.85 & 1.358 & 9.157 & 0.000 \\
\hline
\end{tabular}

Note. ${ }^{\dagger}$ significant standardized residual for Chi Square test. $*$ p value of $\mathrm{F}(\mathrm{ANOVA})<0.001$. No significant residuals were found for the variable: "Who did you quarantine with".

Participants were asked to declare, at the time of the compilation of the questionnaire, the risk of covid-19 transmission within the area they lived, rating the level in: "Low-risk", "Intermediate to low-risk", "Intermediate to high-risk", "High-risk". Students were the least likely to report being in the "high-risk" category, while technical administrative staff were significantly more likely to report to be in a high-risk zone $(24.5 \%)$. Half the students $(50.3 \%)$ declared to be in an intermediate low-risk zone, in a significantly higher percentage than other groups.

Half the technical administrative staff $(52 \%)$ reported that they were not under a form of isolation or restriction (quarantine) when they filled-in the questionnaire.

Almost half the students reported that they didn't spend the March-May 2020 lockdown in the city where their university is located or nearby $(44.7 \%)$.

The majority of respondents (87\%-88\%), in all groups, reported having lived with their family during the lockdown period. Students spent the quarantine period averagely in a family of three persons, a number significantly higher than other groups (Mean: 3.46).

\subsubsection{Household Environment Features where the Respondents Lived during the Lockdown}

We analyzed different aspects of the household environment where the respondents had lived during the first lockdown period, evaluated on a 5-point Likert scale, with the lowest scores indicating a bad quality of environment (e.g.: from less pleasant to more pleasant).

Regarding the quality of the house environment in which they lived during the lockdown, students appeared to be disadvantaged compared to professors and technical administrative staff. Tukey post hoc of the MANOVA revealed that students lived in significantly smaller (Mean: 3.40, SD: 1.14) and more crowded (Mean: 2.72, SD: 1.08) environments, less conveniently positioned with respect to country/city (Mean: 3.83, SD: 1.14) and less pleasant (Mean: 3.83, SD: 1.13).

\subsubsection{Technological Equipment that the Respondents Lived during the Lockdown}

$20 \%$ of technical administrative staff, significantly more than the other groups $(\mathrm{p}<0.01)$, reported they didn't have a device available for personal use during lockdown. Only 33\% of the T.A. has an institutional device $(64.8 \%)$. However, most participants (80\%-95\%) had an adequate device and almost all of them (98\%) had internet access.

Students had an internet connection moderately adequate for their needs but significantly less adequate than other participants, rated on a Likert scale from 1 = "Adequate" to 5 = "Inadequate" (Mean: 2.68, SD: 1.30, $\mathrm{p}<0.01)$. 


\subsubsection{Issues in Studying and Distance Working}

We examined the ratings of the severity of the issues experienced by respondents during lockdown concerning studying and working at distance (rated on a Likert scale, where $0=$ "Not at all", $1=$ "Very little", 2 = "Little", $3=$ "Quite", 4 = "Very much"). Multivariate Analysis of Variance (MANOVA) revealed differences between groups (Table 2).

The highest ratings were found about the relationships with students. Students reported more severe issues in their relationship with other students (Mean: 2.75, SD: 1.19) and with professors than other groups (Mean: 2.32, SD: 1.27, $\mathrm{p}<0.01)$. Professors reported more severe issues in their relationship with students than administrative technical staff (Mean: 2.68, SD: 1.22, p < 0.01). Administrative technical staff, on the other hand, reported less severe relationship issues, either with colleagues or with students.

Table 2. Average scores for the ratings of the difficulties experienced during lockdown concerning studying and working at a distance

\begin{tabular}{|c|c|c|c|c|c|c|c|c|}
\hline \multirow[b]{2}{*}{ Issues } & \multicolumn{2}{|c|}{ Professors } & \multicolumn{2}{|c|}{ Students } & \multicolumn{2}{|c|}{ T.A. Staff } & \multirow{2}{*}{$F_{(2,428)}$} & \multirow[b]{2}{*}{$\mathbf{p}$} \\
\hline & Mean & SD & Mean & SD & Mean & SD & & \\
\hline ...in relationships with professors & 1.66 & 1.200 & $2.32 *$ & 1.270 & 1.62 & 1.228 & 14.855 & 0.000 \\
\hline ...in relationships with students & $2.68 *$ & 1.221 & $2.75 *$ & 1.191 & 1.38 & 1.350 & 54.351 & 0.000 \\
\hline ...in relationships with colleagues & - & - & - & - & 1.83 & 1.326 & - & - \\
\hline$\ldots$ with online exams & 2.12 & 1.256 & 1.97 & 1.280 & - & - & 1.034 & 0.310 \\
\hline$\ldots$ with online lectures & 1.90 & 1.186 & 2.14 & 1.278 & - & - & 2.636 & 0.106 \\
\hline$\ldots$ with administrative activities & 1.65 & 1.115 & - & - & - & - & - & - \\
\hline ...in receiving administrative and technical support & 1.70 & 1.145 & - & - & - & - & - & - \\
\hline$\ldots$ with research activities & 2.55 & 1.387 & - & - & - & - & - & - \\
\hline$\ldots$ with publications & 1.95 & 1.399 & - & - & - & - & - & - \\
\hline ...with administrative procedures & - & - & 2.10 & 1.367 & - & - & - & - \\
\hline ...in receiving technical support & - & - & 2.34 & 1.031 & - & - & - & - \\
\hline ...with online activities & - & - & - & - & 1.90 & 1.408 & - & - \\
\hline ...in receiving managerial support & - & - & - & - & 1.61 & 1.326 & - & - \\
\hline
\end{tabular}

\subsubsection{Stress and Mental Well-being during Lockdown}

Table 3 presents descriptive statistics, $\mathrm{F}$ and $\mathrm{p}$ value of MANOVA about the measures of stress (PSS) and well-being (WEMWBS).

The average level of perceived stress by students (Mean: 9.1, SD: 3.47) was higher than the published normative value (6.7) for a sample of English people in the 19-29 age range (Warttig et al., 2013). Tukey's post hoc test revealed that students had significantly higher scores than other groups $\left(\mathrm{F}_{(2,447)}=35.324\right.$, $\mathrm{p}<0.01)$.

Students perceived a lower level of mental well-being (Mean: 35.51, SD: 7.99) than professor and administrative technical staff $\left(\mathrm{F}_{(2,447)}=24.932, \mathrm{p}<0.01\right)$.

The average score for the well-being scale reported by students was lower than the published value (41.5) for Italian students (Gremigni and Stewart-Brown, 2011), while scores reported by the other two groups of participants were in the same range. 
Table 3. Average scores for the measures of perceived stress and well-being during lockdown

\begin{tabular}{|c|c|c|c|c|c|c|c|c|}
\hline & \multicolumn{2}{|c|}{ Professors } & \multicolumn{2}{|c|}{ Students } & \multicolumn{2}{|c|}{ T.A staff } & \multirow[b]{2}{*}{$F_{(2,447)}$} & \multirow[b]{2}{*}{$\mathbf{p}$} \\
\hline & Mean & SD & Mean & SD & Mean & SD & & \\
\hline Perceived stress (PSS) & 6.23 & 3.294 & $9.11 *$ & 3.473 & 6.29 & 3.416 & 35.324 & 0.000 \\
\hline Well-being (WEMWBS) & 40.32 & 7.955 & 35.51* & 7.993 & 41.62 & 7.748 & 24.932 & 0.000 \\
\hline
\end{tabular}

Note. ${ }^{*} \mathrm{p}<0.01$; $\mathrm{p}$-values of Tuckey's post hoc test for ANOVAS.

\subsubsection{Predictors of Perceived Stress and Well-Being during Lockdown}

We investigated the predictive effects of different variables on respondents' perception of perceived stress and well-being using multiple regression models. Table 4 shows Beta coefficient, $\mathrm{p}$ value and $\mathrm{R}^{2}$ of three multiple regression models to analyze predictors of perceived stress by professors, students and T.A. staff.

Table 4. Multiple regression models: predictors of perceived stress by professors, students and T.A. staff

\begin{tabular}{|c|c|c|c|c|c|c|}
\hline \multirow[b]{2}{*}{ Predictors of Perceived Stress (PSS) } & \multicolumn{2}{|c|}{ Professors } & \multicolumn{2}{|c|}{ Students } & \multicolumn{2}{|c|}{ T.A. Staff } \\
\hline & Beta & $\mathbf{p}$ & Beta & $\mathbf{p}$ & Beta & $\mathbf{p}$ \\
\hline gender & -0.155 & 0.087 & -0.101 & 0.231 & -0.096 & 0.229 \\
\hline age & 0.121 & 0.164 & -0.095 & 0.272 & 0.055 & 0.507 \\
\hline risk of infection & 0.145 & 0.088 & 0.089 & 0.297 & 0.022 & 0.785 \\
\hline restriction/quarantine & -0.099 & 0.248 & 0.060 & 0.465 & 0.108 & 0.187 \\
\hline dwelling size & 0.039 & 0.741 & -0.029 & 0.753 & -0.042 & 0.685 \\
\hline housing density & -0.029 & 0.724 & 0.116 & 0.180 & 0.095 & 0.259 \\
\hline good position & -0.159 & 0.067 & -0.061 & 0.483 & -0.117 & 0.181 \\
\hline good equipment & -0.167 & 0.081 & -0.115 & 0.204 & 0.097 & 0.319 \\
\hline pleasantness & $-0.274 *$ & 0.023 & $-0.314 * *$ & 0.001 & -0.15 & 0.147 \\
\hline relational issues with professors & -0.051 & 0.600 & -0.100 & 0.340 & 0.221 & 0.079 \\
\hline relational issues with students & -0.173 & 0.112 & 0.144 & 0.114 & 0.026 & 0.789 \\
\hline relational issues with colleagues & - & - & - & - & -0.111 & 0.372 \\
\hline issues with online exams & 0.037 & 0.701 & 0.009 & 0.920 & - & - \\
\hline issues with online lectures & $0.297 * *$ & 0.006 & 0.181 & 0.074 & - & - \\
\hline issues with administrative activities & $0.383 * *$ & 0.000 & - & - & - & - \\
\hline issues with administrative technical support & -0.063 & 0.540 & - & - & - & - \\
\hline issues with research activities & -0.010 & 0.935 & - & - & - & - \\
\hline issues with publications & 0.192 & 0.094 & - & - & - & - \\
\hline issues with administrative procedures & - & - & 0.141 & 0.162 & - & - \\
\hline issues with information support & - & - & -0.106 & 0.280 & - & - \\
\hline issues with online activities & - & - & - & - & 0.102 & 0.233 \\
\hline issues with managerial support & - & - & - & - & $0.253 * *$ & 0.007 \\
\hline $\mathrm{N}$ & \multicolumn{2}{|c|}{129} & \multicolumn{2}{|c|}{127} & \multicolumn{2}{|c|}{119} \\
\hline $\mathrm{R}^{2}$ & \multicolumn{2}{|c|}{0.211} & \multicolumn{2}{|c|}{0.224} & \multicolumn{2}{|c|}{0.305} \\
\hline
\end{tabular}


Results showed that for professors (Beta: $-0.274, \mathrm{p}<0.05$ ) and students (Beta: $-0.314, \mathrm{p}<0.01$ ) experiencing an unpleasant house environment is a predictor of perceived stress.

For professors, having issues with online lectures (Beta: 0.297, p < 0.01) and with administrative activities (Beta: $0.383, \mathrm{p}<0.01$ ) significantly predicted a high level of perceived stress.

In addition, perceived stress by technical administrative staff is predicted by having issues with managerial support (Beta: $0.253, \mathrm{p}<0.01$ ). Table 5 shows Beta coefficient, $\mathrm{p}$ value and $\mathrm{R}^{2}$ of three multiple regression models to analyze predictors of well-being by professors, students and T.A. staff.

Table 5. Multiple regression models: predictors of well-being by professors, students and T.A. staff

\begin{tabular}{|c|c|c|c|c|c|c|}
\hline \multirow[b]{2}{*}{$\begin{array}{l}\text { Predictors of Mental Well-being } \\
\text { (WEMWBS) }\end{array}$} & \multicolumn{2}{|c|}{ Professors } & \multicolumn{2}{|c|}{ Students } & \multicolumn{2}{|c|}{ T.A. Staff } \\
\hline & Beta & $\mathbf{p}$ & Beta & $\mathbf{p}$ & Beta & $\mathbf{p}$ \\
\hline gender & 0.031 & 0.753 & $0.211 *$ & 0.012 & 0.122 & 0.124 \\
\hline age & -0.135 & 0.162 & 0.117 & 0.170 & 0.017 & 0.835 \\
\hline risk of infection & 0.040 & 0.669 & -0.027 & 0.747 & -0.021 & 0.796 \\
\hline restriction/quarantine & 0.073 & 0.440 & 0.035 & 0.659 & 0.022 & 0.789 \\
\hline dwelling size & -0.144 & 0.272 & 0.003 & 0.972 & 0.166 & 0.107 \\
\hline housing density & 0.125 & 0.171 & -0.070 & 0.407 & 0.08 & 0.333 \\
\hline good position & 0.035 & 0.717 & 0.083 & 0.332 & $0.218 *$ & 0.012 \\
\hline good equipment & 0.130 & 0.221 & 0.055 & 0.532 & -0.007 & 0.938 \\
\hline pleasantness & $0.269 *$ & 0.044 & $0.306 * *$ & 0.001 & 0.190 & 0.063 \\
\hline relational issues with professors & -0.032 & 0.768 & 0.046 & 0.652 & -0.053 & 0.669 \\
\hline relational issues with students & -0.055 & 0.648 & $-0.214 *$ & 0.017 & -0.009 & 0.928 \\
\hline relational issues with colleagues & - & - & - & - & -0.04 & 0.744 \\
\hline issues with online exams & 0.053 & 0.619 & -0.087 & 0.302 & - & - \\
\hline issues with online lectures & 0.012 & 0.920 & -0.068 & 0.492 & - & - \\
\hline issues with administrative activities & -0.055 & 0.637 & - & - & - & - \\
\hline issues with administrative technical support & -0.137 & 0.233 & - & - & - & - \\
\hline issues with research activities & -0.049 & 0.707 & - & - & - & - \\
\hline issues with publications & -0.117 & 0.355 & - & - & - & - \\
\hline issues with administrative procedures & - & - & 0.040 & 0.686 & - & - \\
\hline issues with information support & - & - & 0.004 & 0.969 & - & - \\
\hline issues with online activities & - & - & - & - & -0.147 & 0.084 \\
\hline issues with managerial support & - & - & - & - & $-0.221 *$ & 0.016 \\
\hline $\mathrm{N}$ & \multicolumn{2}{|c|}{112} & \multicolumn{2}{|c|}{127} & \multicolumn{2}{|c|}{119} \\
\hline $\mathrm{R} 2$ & \multicolumn{2}{|c|}{0.159} & \multicolumn{2}{|c|}{0.253} & \multicolumn{2}{|c|}{0.322} \\
\hline
\end{tabular}

Note. $* \mathrm{p}<0.05, * * \mathrm{p}<0.01$.

As expected, pleasantness of the house environment is a predictor of high level of well-being for professors (Beta: 0.269, $\mathrm{p}<0.05$ ) and students (Beta: 0.306, $\mathrm{p}<0.01$ ). 
Having relational issues with other students is a significant negative predictor (Beta: $-0.214, p<0.05$ ) of well-being in the student group, while being male is a positive predictor of mental well-being.

On the other hand, for technical administrative employees, being in a good position with respect to country/city (Beta: 0.218, $\mathrm{p}<0.05$ ) and not having issues with managerial support (Beta: $-0.221, \mathrm{p}<0.05)$ are positive predictors of mental well-being.

\section{CONCLUSION}

University students, teachers, and technical-administrative staff who participated in the study reported different problems with a different level of severity. Aspects related to housing situations are likely to refer to differentiated socio-economic conditions for which social and political interventions are necessary and that can be only marginally influenced by university institutions. In this regard, teachers and students seem to be particularly affected by the level of pleasantness of their housing, while administrative technicians are more likely to suffer from the poor location of their housing. Possible solutions to these problems are not always addressable by higher education institutions which may not have the economic strength to cope with these issues. However, especially for the most fragile, such as students with disabilities, this can be particularly relevant, and interventions aimed at fostering awareness of the need for institutional intervention can produce significant results (Fernández-Gámez et al., 2020).

The main problems for all the three groups of participants, however, are more likely to be related to issues on which it is easier to intervene, because they refer to the possibility of having adequate social relations and receiving efficient informative support. This is particularly relevant for students, who reported alarming levels of stress, and higher than other groups. It is evident that, especially in circumstances of isolation, higher education institutions must know how to organize students' peer support (Gallop and Bastien, 2016) and facilitate participation in online academic social networks. This type of intervention is linked to the possibility of increasing general levels of well-being and limiting the occurrence of marginalization phenomena (Parlangeli et al., 2019; Mishra, 2020). The opportunities that online communication can offer is also relevant for professors and administrative technical staff, even if the needs they express seem less urgent and are, above all, different. For professors, in fact, the need to have adequate ICTs for activities such as online exams and the execution of administrative procedures can be highlighted. The technical-administrative personnel, on the other hand, are suffering from the distance from managers that results in a lack of adequate support. The possibility to have ICTs with an adequate level of usability (Vlachogianni and Tselios, 2021), along with widespread, stable and broadband connectivity opportunities, is a primary need that cannot be further delayed.

\section{REFERENCES}

Akour, A. et al, 2020. The Impact of the COVID-19 Pandemic and Emergency Distance Teaching on the Psychological Status of University Teachers: A Cross-Sectional Study in Jordan. The American Journal of Tropical Medicine and Hygiene, Vol. 103, No. 6, pp. 2391-2399. DOI: 10.4269/ajtmh.20-0877.

Al Issa, H.-E. and Jaleel, E.M. 2021. Social isolation and psychological wellbeing: lessons from Covid-19. Management Science Letters, Vol. 11, No. 2, pp. 609-618. DOI: 10.5267/j.msl.2020.9.006.

Angeli, C. and Valanides, N. 2005. Preservice elementary teachers as information and communication technology designers: an instructional systems design model based on an expanded view of pedagogical content knowledge. Journal of Computer Assisted Learning, Vol. 21, No. 4, pp. 292-302. DOI: 10.1111/j.1365-2729.2005.00135.x.

Baldwin, S.J. et al, 2018. Online course design and development among college and university instructors: An analysis using grounded theory. Online Learning Journal, Vol. 22, No. 2, pp. 157-172. DOI: 10.24059/olj.v22i2.1212.

Cao, W. et al, 2020. The psychological impact of the COVID-19 epidemic on college students in China. Psychiatry Research, Vol. 287. DOI: 10.1016/j.psychres.2020.112934.

Cohen, S. et al. 1983. A Global Measure of Perceived Stress. Journal of Health and Social Behavior Vol. 24, No. 4, pp. 385-396. DOI:10.2307/2136404.

Courtin, E. and Knapp, M. 2017. Social isolation, loneliness and health in old age: a scoping review. Health \& Social Care in the Community, Vol. 25, No. 3. DOI: 10.1111/hsc.12311. 
Duan, L. and Zhu, G. 2020. Psychological interventions for people affected by the COVID-19 epidemic. The Lancet Psychiatry, Vol. 7, No. 4, pp. 300-302. DOI: 10.1016/S2215-0366(20)30073-0.

Elmer, T. et al, 2020. Students under lockdown: Comparisons of students' social networks and mental health before and during the COVID-19 crisis in Switzerland. PLoS ONE, Vol. 15, No. 7, e0236337. doi: 10.1371/journal.pone.0236337.

Fernández-Gámez M. A. et al, 2020. Innovative interventions and provisions of accommodations to students with disabilities. European Journal of Special Needs Education, pp. 1-10. DOI: 10.1080/08856257.2020.1792715.

Gallop, C.J. and Bastien N. 2016. Supporting Success: Aboriginal students in higher education. Canadian Journal of Higher Education, Vol.46, No. 2, pp. 206-224. DOI: 10.47678/cjhe.v46i2.184772.

Gremigni, P. and Stewart-Brown, S. 2011. Una misura del benessere mentale: validazione italiana della Warwick-Edinburgh Mental Well-Being Scale (WEMWBS). Giornale Italiano Di Psicologia., Vol. 2, pp. $485-508$. DOI: $10.13140 / 2.1 .2425 .9203$.

Hossain, M.M. et al, 2020. Mental health outcomes of quarantine and isolation for infection prevention: A systematic umbrella review of the global evidence. Epidemiology and Health, Vol. 42, pp. 1-11. DOI: 10.4178/epih.e2020038.

Kali, Y. et al, 2011. Researching design practices and design cognition: contexts, experiences and pedagogical knowledge-in-pieces. Learning, Media and Technology, Vol. 36, No. 2, pp. 129-149. doi: 10.1080/17439884.2011.553621.

King, C.G. et al, 2009. Online exams and cheating: An empirical analysis of business students' views. Journal of Educators Online, Vol. 6, No. 1, pp. 1-11. DOI: 10.9743/jeo.2009.1.1.

Kiplangat, H.K. et al, 2016. Challenges Encountered by University Administrators in Performance Management and Job Satisfaction of Academic Staff in Kenyan Universities The Catholic University of Eastern Africa The Catholic University of Eastern Africa. Journal of Emerging Trends in Educational Research and Policy Studies, Vol. 7, No. 6, pp. 383-390.

Mishra S. 2020. Social networks, social capital, social support and academic success in higher education: A systematic review with a special focus on 'underrepresented' students. Educational Research Review, Vol. 29, No. 1, 100307, DOI: $10.1016 /$ j.edurev.2019.100307.

Mukhtar, S. 2020. Psychological impact of COVID-19 on older adults. Current Medicine Research and Practice, Vol. 10, No. 4, pp. 201-202. DOI: 10.1016/j.cmrp.2020.07.016.

Odriozola-González, P. et al, 2020. Psychological effects of the COVID-19 outbreak and lockdown among students and workers of a Spanish university. Psychiatry Research, Vol. 290. DOI: 10.1016/j.psychres.2020.113108.

Parlangeli, O. et al, 2017. Stress and Unethical Behaviour in the Research of the Untenured University Researchers. ICERI, 10th International Conference of Education Research and Innovation, Seville, Spain. DOI: 10.21125/iceri.2017.0585.

Parlangeli, O. et al, 2011. The effect of system usability and multitasking activities in distance learning. Proceedings of the 9th ACM SIGCHI Italian Chapter International Conference on Computer-Human Interaction Facing Complexity - CHItaly, ACM Press, New York, New York, USA. DOI: 10.1145/2037296.2037314.

Parlangeli, O. et al, 2018. Stress misconduct and reduced ability to express dissent: A study on a sample of students at the University of Siena. in J.B. P.M. Arezes (Ed.), Occupational Safety and Hygiene. Vol. VI, CRC Press, Taylor \& Francis Group, London, pp. 443-446. DOI: 10.1201/9781351008884-78.

Parlangeli O. et al, 2019. Offensive acts and helping behavior on the internet: An analysis of the relationships between moral disengagement, empathy and use of social media in a sample of Italian students. Work, Vol. 63, No. 3, 469-477. DOI: $10.3233 /$ WOR-192935.

Rogowska, A.M. et al, 2020. Examining Anxiety, Life Satisfaction, General Health, Stress and Coping Styles During COVID-19 Pandemic in Polish Sample of University Students. Psychology Research and Behavior Management, Vol. 13, pp. 797-811. DOI: 10.2147/PRBM.S266511

Sahu, P. 2020. Closure of Universities Due to Coronavirus Disease 2019 (COVID-19): Impact on Education and Mental Health of Students and Academic Staff. Cureus, Vol. 12, No. 4, e7541. DOI: 10.7759/cureus.7541

Shah, K. et al, 2020. Impact of COVID-19 on the Mental Health of Children and Adolescents. Cureus, Vol. 12, No. 8, e10051. DOI: 10.7759 /cureus.10051.

Tennant R. et al. 2007. The Warwick-Edinburgh Mental Well-being Scale (WEMWBS): Development and UK validation. Health and Quality of Life Outcomes. Vol. 5, No. 63, DOI: 10.1186/1477-7525-5-63.

Timmis, S. et al, 2016. Rethinking assessment in a digital age: opportunities, challenges and risks. British Educational Research Journal, Vol. 42, No. 3, pp. 454-476. DOI: 10.1002/berj.3215.

Vlachogianni, P. and Tselios, N. 2021. Perceived usability evaluation of educational technology using the System Usability Scale (SUS): A systematic review. Journal of Research on Technology in Education, pp. 1-18. doi: $10.1080 / 15391523.2020 .1867938$ 
Wagner, K.D. 2020. Addressing the experience of children and adolescents during the CoviD-19 pandemic. Journal of Clinical Psychiatry, Vol. 81, No. 3, 20ed13394. DOI: 10.4088/JCP.20ed13394.

Wang, C. et al, 2020. Immediate psychological responses and associated factors during the initial stage of the 2019 coronavirus disease (COVID-19) epidemic among the general population in China. International Journal of Environmental Research and Public Health, Vol. 17, No. 5, 1729. DOI: 10.3390/ijerph17051729.

Warttig, S.L. et al, 2013. New, normative, English-sample data for the Short Form Perceived Stress Scale (PSS-4). Journal of Health Psychology, Vol. 18, No. 12, pp. 1617-28. DOI: 10.1177/1359105313508346.

Watson, G. and Sottile, J. 2010. Cheating in the Digital Age: Do Students Cheat More in Online Courses?. Online Journal of Distance Learning Administration, Vol. 13, No. 1. DOI: 10.1016/j.chbr.2020.100033.

Xiao, C. 2020. A novel approach of consultation on 2019 novel coronavirus (COVID-19)-related psychological and mental problems: Structured letter therapy. Psychiatry Investigation, Vol. 17, No. 2, pp. 175-176. doi: 10.30773/pi.2020.0047. 